\title{
Synthesis and catalytic properties of iron-cerium phosphate prepared in ethylene glycol using additives
}

\author{
Hiroaki ONODA*, Takeshi SAKUMURA \\ Department of Informatics and Environmental Sciences, Kyoto Prefectural University, 1-5, \\ Shimogamo Nakaragi-cho, Sakyo-ku, Kyoto 606-8522, Japan
}

Received: November 24, 2012; Revised: January 22, 2013; Accepted: January 23, 2013

(C) The Author(s) 2013. This article is published with open access at Springerlink.com

\begin{abstract}
The effects of cerium substitution, use of additives, and heating temperature on the chemical composition and catalytic activity of iron phosphate were evaluated. Iron-cerium phosphate was prepared from iron nitrate, ammonium cerium nitrate, and sodium phosphate in ethylene glycol using sodium dodecyl-sulfate or acetylacetone as additive. The chemical composition, particle shape and size distribution of the obtained samples were respectively evaluated based on ICP and XRD, SEM, and laser diffraction/scattering analysis. The catalytic activity was evaluated based on the decomposition of the complex formed from formaldehyde, ammonium acetate, and acetylacetone. XRD peaks corresponding to $\mathrm{FePO}_{4}$ were observed for the samples heated at $600{ }^{\circ} \mathrm{C}$ whereas samples treated at lower temperatures were amorphous. Iron-cerium phosphates heated at $200{ }^{\circ} \mathrm{C}$ and $400{ }^{\circ} \mathrm{C}$ exhibited high catalytic activity for the decomposition of the aforementioned complex.
\end{abstract}

Keywords: iron phosphate; cerium substitution; ethylene glycol; ICP analysis; catalytic property

\section{Introduction}

Phosphates have been used as ceramic materials, catalysts, fluorescent materials and dielectric substances in metal surface treatment, and as detergents, food additives, fuel cells, pigments, etc. [1-3]. Catalyst application is one of the most important uses of phosphate materials, exemplified by the use of vanadium phosphate as a catalyst for the oxidation of butane [4], nickel phosphate for oxidizing alcohols [5], and iron phosphate for the oxidation of methane [6]. Furthermore, aluminum phosphate is an effective catalyst in the dehydration of alcohols [7], and other phosphates, such as zirconium, cobalt and potassium phosphates, are also recognized as important catalysts

* Corresponding author.

E-mail: onoda@kpu.ac.jp
[8-10]. The catalytic reactions referenced so far were generally performed in gas phase. Catalytic reactions in aqueous solutions are also important for obtaining certain target materials; however, studies on phosphate catalysts in aqueous solutions are limited owing to their solubility in acidic and basic solutions.

Transition-metal phosphates sometimes have nonstoichiometric cation/phosphorus ratios because of the presence of hydrogen cations, hydroxide anions, etc. These hydrogen cations and hydroxide anions influence the catalytic activity of phosphate materials owing to the formation of hydrogen sites on the phosphate surface. Because these transition-metal phosphates function as solid-state acidic catalysts, control of their synthesis conditions is important in determining the chemical composition of phosphate materials. Generally, the use of additives in the preparation process facilitates the generation of the target phosphate material particles [11]. Spherical and 
porous particles of lanthanum phosphate have been obtained by the addition of urea [12]. Herein, either sodium dodecyl-sulfate (SDS) or acetylacetone (acac) was used as an additive to prevent aggregation during the preparation of iron-cerium phosphate. Ethylene glycol, which has a higher viscosity than water, was used as a solvent.

The use of transition-metal phosphates in acidic and basic solutions is limited by their solubility. In a previous work, elution of the phosphates was inhibited by substitution with rare-earth cations [13]. Therefore, rare-earth substituted iron phosphates may potentially be used as catalysts in solution.

In this work, iron-cerium phosphate was prepared from iron nitrate, ammonium cerium nitrate, and sodium phosphate using SDS or acac in ethylene glycol. The effect of varying the ratios of iron/cerium and SDS/phosphorus during the preparation was evaluated. The particles' shape and size distribution and catalytic activity of the obtained products were also evaluated, with the overall objective of elucidating the influence of cerium substitution, additives, and heating temperature on the chemical composition and catalytic activity of iron phosphate.

\section{Experimental procedure}

A solution of $0.2 \mathrm{~mol} / \mathrm{L}$ iron nitrate, $\mathrm{Fe}\left(\mathrm{NO}_{3}\right)_{3}$, in ethylene glycol was mixed with $0.2 \mathrm{~mol} / \mathrm{L}$ solution of sodium phosphate, $\mathrm{Na}_{3} \mathrm{PO}_{4}$, in ethylene glycol at $\mathrm{Fe} / \mathrm{P}$ molar ratio of $1: 1$. This ratio was selected based on the chemical composition of iron orthophosphate, $\mathrm{FePO}_{4}$. SDS or acac was added to the mixed solution in a ratio of $\mathrm{Fe}: \mathrm{SDS}=1: 1$ or $\mathrm{Fe}: \mathrm{acac}=1: 3$ to prevent particle aggregation. The mixed solution without additives was also prepared as a control, which was stirred for $24 \mathrm{~h}$. The resulting precipitates were collected by decanting and dried at $60{ }^{\circ} \mathrm{C}$ in air. Cerium-substituted samples were also prepared for comparison with iron phosphate by substituting a portion of the iron nitrate with ammonium cerium nitrate, $\left(\mathrm{NH}_{4}\right)_{2} \mathrm{Ce}\left(\mathrm{NO}_{3}\right)_{6}$, in a ratio of $\mathrm{Fe}: \mathrm{Ce}=8: 2$. Thus, four trivalent iron cations were replaced with three cerium tetravalent cations. In this work, the ratio of $\mathrm{P}:(3 \mathrm{Fe}+4 \mathrm{Ce})$ was $1: 3$. All chemicals were of commercial purity from Wako Chemical Industries Ltd. (Osaka, Japan) and used without further purification.

Part of the precipitates was dissolved in hydrochloric acid solution and the ratio of phosphorus, iron and cerium in the precipitates was calculated by their inductively coupled plasma (ICP, SPS1500VR, Seiko Instruments Inc.) analysis. The thermal behavior of these materials was analyzed via X-ray diffraction (XRD). XRD patterns were recorded on a Rigaku MiniFlex X-ray Diffractometer using monochromated $\mathrm{Cu} \mathrm{K} \alpha$ radiation.

Shape and size distribution properties of the powders generated under thermal conditions of $60{ }^{\circ} \mathrm{C}$, $200{ }^{\circ} \mathrm{C}, 400{ }^{\circ} \mathrm{C}$, and $600{ }^{\circ} \mathrm{C}$ were characterized via scanning electron micrography (SEM) using a JGM-5510LV, JEOL Ltd. Instrument and laser diffraction/scattering analysis on a HORIBA LA-910 Instrument, respectively.

Further, to investigate the application of phosphates, the catalytic activity of iron-cerium phosphate was studied in the decomposition of the complex generated from the following reaction:

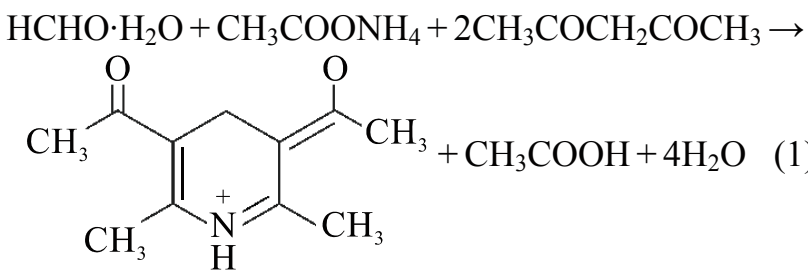

In this reaction, formaldehyde forms a complex with ammonium acetate and acac. This complex absorbs light at $415 \mathrm{~nm}$. Metal phosphate samples were added to the reaction solution, which was then shaken for $24 \mathrm{~h}$. Decomposition of the complex occurs in the presence of a strong catalyst. Thus, the catalytic activity of iron-cerium phosphate could be monitored on the basis of reduction in absorption at $415 \mathrm{~nm}$.

\section{Results and discussion}

\section{1 Chemical composition and powder properties of iron-cerium phosphates}

All obtained samples were yellow powders, and thus it could be deduced that iron in the precipitates was mainly in the trivalent state. Table 1 shows the chemical composition of the precipitates based on ICP analysis. Because the $\mathrm{Fe} / \mathrm{P}$ ratio in iron phosphate, $\mathrm{FePO}_{4}$, is 1 , the samples contained a certain amount of protons such as $\mathrm{Fe}_{0.617} \mathrm{H}_{1.149} \mathrm{PO}_{4}$. The protons in this chemical formula indicate the presence of ammonium and sodium cations. The presence of protons is important for use as a phosphate catalyst. These compounds were expected to act as Brønsted catalysts. The addition of acac increased the ratio of protons. The actual cerium ratio in the precipitates was lower than 
the nominal value of the precursor. In previous studies $[14,15]$, the lanthanum ratio in the precipitates was higher than the nominal value. This difference is considered to be related to the valence state of the rare-earth cations. In the present case, cerium is in the tetravalent state, whereas the lanthanum cations in the previous study were trivalent. The trivalent rare-earth cations react readily with the phosphate materials. Trivalent rare-earth phosphates are a main constituent of Monazite ore and are insoluble in acidic and basic solution when present in phosphate materials. The addition of SDS exerted less influence on the $\mathrm{Fe} / \mathrm{Ce}$ ratio in the precipitate.

Table 1 Chemical composition of precipitates from ICP measurements

\begin{tabular}{crccccc}
\hline & \multicolumn{2}{c}{ Preparation } & & \multicolumn{3}{c}{ Precipitate, $\mathrm{Fe}_{x} \mathrm{Ce}_{y} \mathrm{H}_{z} \mathrm{PO}_{4}$} \\
\cline { 2 - 7 } \cline { 5 - 7 } & $\mathrm{Fe}: \mathrm{Ce}$ & Additive & $x$ & $y$ & $z$ & $\mathrm{Fe}: \mathrm{Ce}$ \\
\hline $\mathrm{A}$ & $10: 0$ & - & 0.617 & - & 1.149 & - \\
$\mathrm{B}$ & $8: 2$ & - & 0.591 & 0.078 & 0.915 & $8: 1.06$ \\
$\mathrm{C}$ & $10: 0$ & SDS & 0.695 & - & 0.915 & - \\
$\mathrm{D}$ & $8: 2$ & SDS & 0.567 & 0.092 & 0.931 & $8: 1.30$ \\
$\mathrm{E}$ & $10: 0$ & acac & 0.584 & - & 1.248 & - \\
$\mathrm{F}$ & $8: 2$ & acac & 0.525 & 0.060 & 1.185 & $8: 0.91$ \\
\hline
\end{tabular}

The XRD patterns showed that the samples heated at $60{ }^{\circ} \mathrm{C}, \quad 200{ }^{\circ} \mathrm{C}$, and $400{ }^{\circ} \mathrm{C}$ were amorphous. Amorphous phosphate materials are expected to have various kinds of acidic sites, and therefore, function as acidic catalysts. Figure 1 shows the XRD patterns of

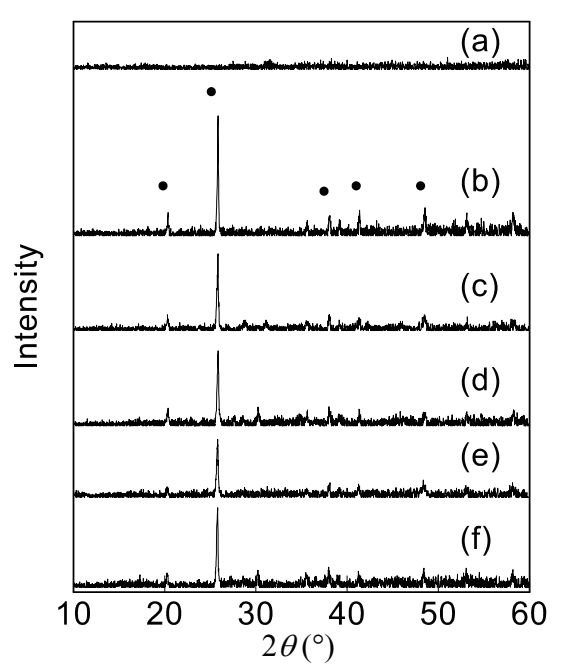

Fig. 1 XRD patterns of samples heated at $600{ }^{\circ} \mathrm{C}$ : (a) $\mathrm{Fe}: \mathrm{Ce}=10: 0$, no additive; (b) $\mathrm{Fe}: \mathrm{Ce}=8: 2$, no additive; (c) $\mathrm{Fe}: \mathrm{Ce}=10: 0$, SDS; (d) $\mathrm{Fe}: \mathrm{Ce}=8: 2$, SDS; (e) $\mathrm{Fe}: \mathrm{Ce}=10: 0$, acac; (f) $\mathrm{Fe}: \mathrm{Ce}=8: 2$, acac; $\bullet$ is $\mathrm{FePO}_{4}$. the samples heated at $600{ }^{\circ} \mathrm{C}$. The sample prepared at a ratio of $\mathrm{Fe}: \mathrm{Ce}=10: 0$ without using any additives was amorphous. Peaks corresponding to iron phosphate were observed for the other samples. The sample prepared at a ratio of $\mathrm{Fe}: \mathrm{Ce}=10: 0$ without any additives was considered to crystallize at a temperature slightly above $600{ }^{\circ} \mathrm{C}$. No peak corresponding to cerium compounds was apparent in the XRD patterns. Thus, from the XRD patterns, it is deduced that the tetravalent cerium cations do not react readily with the phosphate anion, which is consistent with the ICP results presented above.

Figure 2 shows the SEM images of samples prepared under various conditions. No specific shapes were observed in this work. Substitution with the cerium cations generated smaller particles, as shown in Figs. 2(a) and 2(b). The addition of SDS and acac further decreased the particle size of the phosphates (Figs. 2(b)-2(d)). These additives prevented the growth of the phosphate particles. The heating temperature had no influence on the shape of the iron-cerium phosphate particles (Figs. 2(b), 2(e) and 2(f)). The particle-size distribution in water was estimated on the basis of laser diffraction/scattering analysis. Figure 3 shows the particle-size distribution of the samples prepared with various additives. The particle sizes of the samples ranged from $2 \mu \mathrm{m}$ to $400 \mu \mathrm{m}$. The number of large particles was reduced by the addition of SDS, consistent with the SEM results. The sample prepared at a ratio of $\mathrm{Fe}: \mathrm{Ce}=8: 2$ had smaller particles than the $\mathrm{Fe}: \mathrm{Ce}=10: 0$ sample (not shown). The heating temperature had little effect on the particle-size distribution of the iron-cerium phosphate samples. Table 2 shows the average particle sizes of the samples based on the particle-size distribution, which was less than $60 \mu \mathrm{m}$ for most of the samples. The samples prepared in ethylene glycol had smaller particle sizes than those prepared in water (not shown) because the high viscosity of ethylene glycol prevented the aggregation of the phosphate particles. These small particles were suitable as phosphate catalysts owing to their potentially large contact area.

Table 2 Average particle sizes of the samples from particle-size distribution

\begin{tabular}{crcrrrrr}
\hline & \multicolumn{2}{c}{ Preparation } & & \multicolumn{3}{c}{ Average particle size $(\mu \mathrm{m})$} \\
\cline { 2 - 3 } \cline { 5 - 7 } & Fe :Ce & Additive & & $60{ }^{\circ} \mathrm{C}$ & $200{ }^{\circ} \mathrm{C}$ & $400{ }^{\circ} \mathrm{C}$ & $600{ }^{\circ} \mathrm{C}$ \\
\hline $\mathrm{A}$ & $10: 0$ & - & & 68.5 & 62.8 & 60.8 & 37.1 \\
$\mathrm{~B}$ & $8: 2$ & - & & 52.6 & 49.8 & 59.6 & 47.4 \\
$\mathrm{C}$ & $10: 0$ & $\mathrm{SDS}$ & & 48.8 & 102.6 & 82.1 & 131.1 \\
$\mathrm{D}$ & $8: 2$ & $\mathrm{SDS}$ & & 37.4 & 55.5 & 54.2 & 97.2 \\
$\mathrm{E}$ & $10: 0$ & $\mathrm{acac}$ & & 43.4 & 52.3 & 43.6 & 38.6 \\
$\mathrm{~F}$ & $8: 2$ & $\mathrm{acac}$ & 66.4 & 66.5 & 57.1 & 51.7 \\
\hline
\end{tabular}



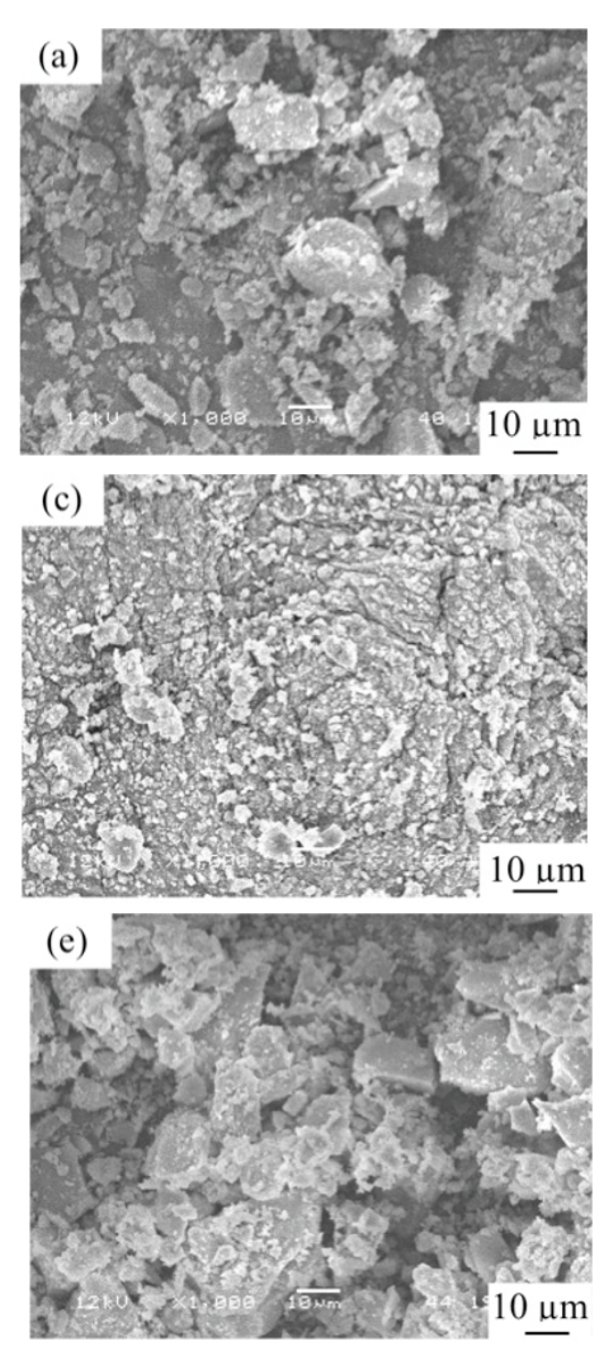
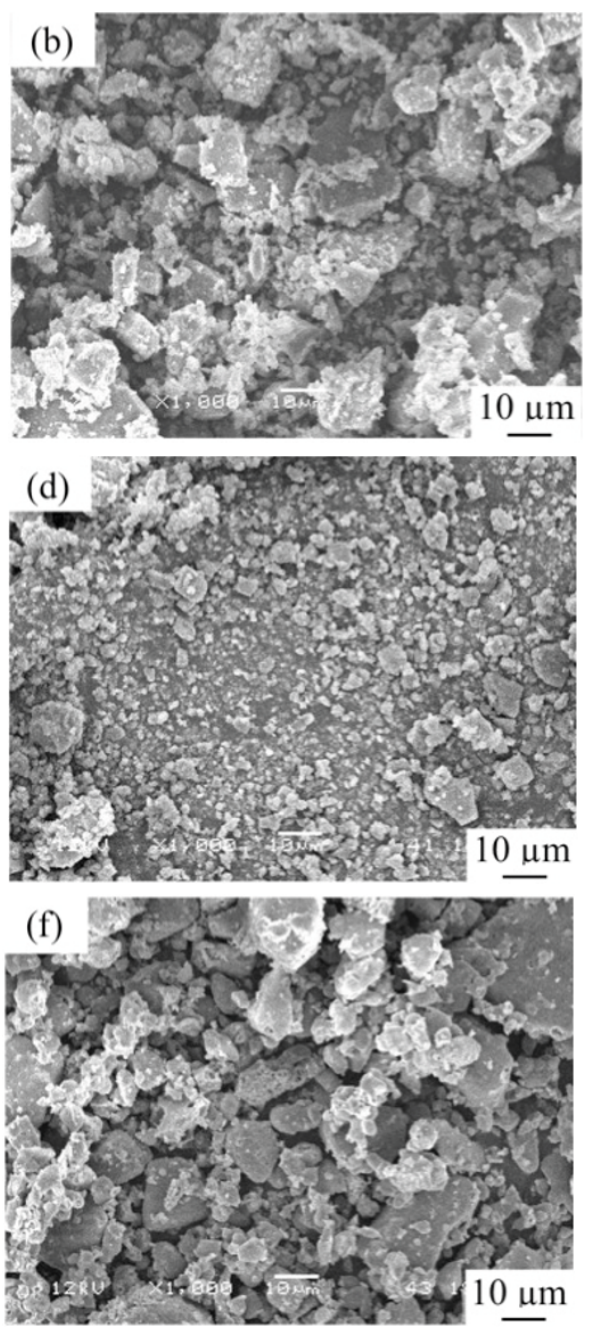

Fig. 2 SEM images of samples prepared under various conditions: (a) $\mathrm{Fe}: \mathrm{Ce}=10: 0$, no additive, $60{ }^{\circ} \mathrm{C}$; (b) $\mathrm{Fe}: \mathrm{Ce}=8: 2$, no additive, $60{ }^{\circ} \mathrm{C}$; (c) $\mathrm{Fe}: \mathrm{Ce}=8: 2$, SDS, $60{ }^{\circ} \mathrm{C}$; (d) $\mathrm{Fe}: \mathrm{Ce}=8: 2$, acac, $60{ }^{\circ} \mathrm{C}$; (e) $\mathrm{Fe}: \mathrm{Ce}=8: 2$, no additive, $400{ }^{\circ} \mathrm{C}$; (f) $\mathrm{Fe}: \mathrm{Ce}=8: 2$, no additive, $600{ }^{\circ} \mathrm{C}$.

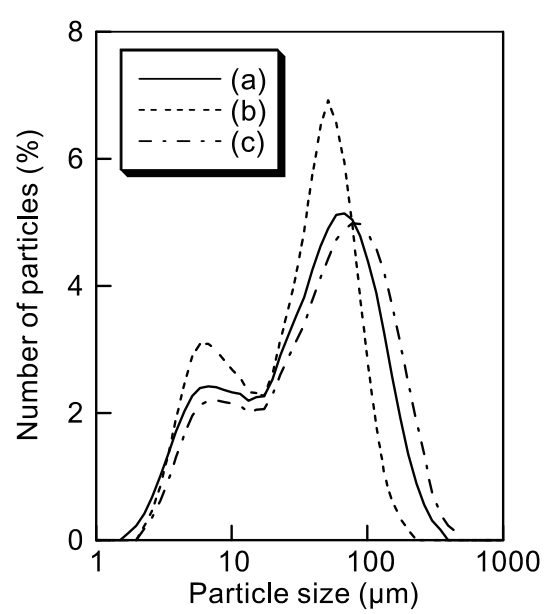

Fig. 3 Particle-size distribution of samples $(\mathrm{Fe}: \mathrm{Ce}=$ $8: 2,60{ }^{\circ} \mathrm{C}$ ): (a) no additive; (b) SDS; (c) acac.

\section{2 Catalytic properties of iron-cerium phosphates}

Figure 4 shows the catalytic activity (based on the adsorption at $415 \mathrm{~nm}$ ) of the $\mathrm{Fe}: \mathrm{Ce}=8: 2$ samples prepared with various additives. The residual ratio of the absorbance was calculated on the basis of the absorbance without catalyst. A low residual ratio is indicative of high catalytic activity of the iron-cerium phosphates. A residual ratio of about $30 \%$ was achieved with sulfuric acid, a typical acidic catalyst, under the present conditions. A previous work demonstrated that iron phosphates heated at $60{ }^{\circ} \mathrm{C}$ and $600{ }^{\circ} \mathrm{C}$ exhibited low catalytic activity [16]. Herein, the samples heated at $60{ }^{\circ} \mathrm{C}$ were characterized by large particles with a consequently reduced the number of acidic sites on the surface of the particles. Based on 
the results obtained with the samples heated at $600{ }^{\circ} \mathrm{C}$, the crystalline iron phosphate was considered to have little catalytic activity. These results were consistent with the general tendency that amorphous materials exhibit higher catalytic activity than crystalline materials. Low catalytic activity was observed for the $\mathrm{Fe}: \mathrm{Ce}=8: 2$ samples that were heated at $60{ }^{\circ} \mathrm{C}$ and $600{ }^{\circ} \mathrm{C}$, also consistent with the previous work. The samples prepared with SDS exhibited enhanced catalytic activity relative to the other samples. The $\mathrm{Fe}: \mathrm{Ce}=10: 0$ samples that were heated at $60{ }^{\circ} \mathrm{C}$ and $600{ }^{\circ} \mathrm{C}$ also had low catalytic activity (not shown).

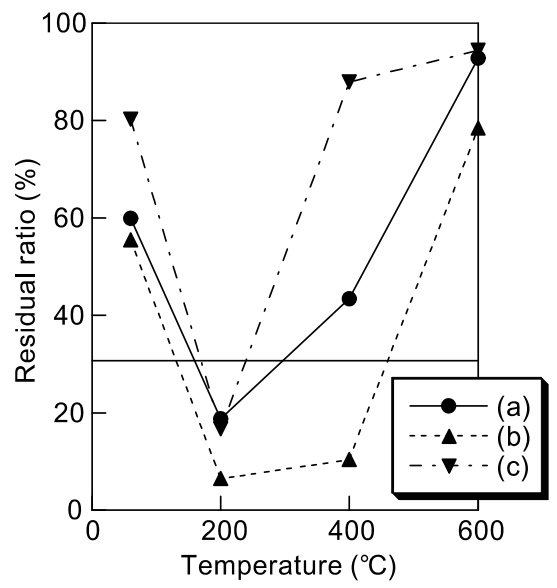

Fig. 4 Catalytic activity of samples prepared at $\mathrm{Fe}: \mathrm{Ce}=8: 2$ ratio: (a) no additive; (b) SDS; (c) acac.

\section{Conclusions}

Iron-cerium phosphates were prepared from iron nitrate, ammonium cerium nitrate, and sodium phosphate in ethylene glycol using various additives. Iron was mainly in the trivalent state in the obtained phosphates, as evidenced by the yellow color. All of the prepared samples had a high hydrogen ratio notwithstanding the variation of the $\mathrm{Fe} / \mathrm{Ce}$ ratio and additives. Peaks corresponding to $\mathrm{FePO}_{4}$ were observed in the XRD patterns of the samples heated at $600{ }^{\circ} \mathrm{C}$. Larger particle size was obtained using a ratio of $\mathrm{Fe}: \mathrm{Ce}=8: 2$ than in the absence of $\mathrm{Ce}$ (i.e., $\mathrm{Fe}: \mathrm{Ce}=10: 0)$. Samples prepared at a ratio of $\mathrm{Fe}: \mathrm{Ce}=8: 2$ in the presence of SDS exhibited high catalytic activity for the decomposition of the complex formed from formaldehyde, ammonium acetate and acac.
Open Access: This article is distributed under the terms of the Creative Commons Attribution Noncommercial License which permits any noncommercial use, distribution, and reproduction in any medium, provided the original author(s) and source are credited.

\section{References}

[1] Onoda H, Nariai H, Moriwaki A, et al. Formation and catalytic characterization of various rare earth phosphates. J Mater Chem 2002, 12: 1754-1760.

[2] Onoda H, Ohta T, Tamaki J, et al. Decomposition of trifluoromethane over nickel pyrophosphate catalysts containing metal cation. Appl Catal A 2005, 288: 98-103.

[3] Onoda H, Yokouchi K, Kojima K, et al. Addition of rare earth cation on formation and properties of various cobalt phosphates. Mat Sci Eng B 2005, 116: 189-195.

[4] Tang WJ. Physico-chemical properties and oxygen species behavior of bulk and modified vanadium phosphate catalyst for partial oxidation of N-butane. Ph.D. Thesis. Malaysia: University Putra, 2008.

[5] Li CL, Kawada H, Sun XY, et al. Highly efficient alcohol oxidation on nanoporous VSB-5 nickel phosphate catalyst functionalized by $\mathrm{NaOH}$ treatment. Chem CatChem 2011, 3: 684-689.

[6] Wang X, Wang Y, Tang Q, et al. MCM-41-supported iron phosphate catalyst for partial oxidation of methane to oxygenates with oxygen and nitrous oxide. $J$ Catal 2003, 217: 457-467.

[7] Yaripour F, Baghaei F, Schmidt I, et al. Synthesis of dimethyl ether from methanol over aluminium phosphate and silica-titania catalysts. Catal Commun 2005, 6: 542-549.

[8] Li N, Tompsett GA, Huber GW. Renewable high-octane gasoline by aqueous-phase hydrodeoxygenation of $\mathrm{C}_{5}$ and $\mathrm{C}_{6}$ carbohydrates over $\mathrm{Pt} /$ zirconium phosphate catalysts. ChemSusChem 2010, 3: 1154-1157.

[9] Zhong DK, Cornuz M, Sivula K, et al. Photo-assisted electrodeposition of cobalt-phosphate (Co-Pi) catalyst on hematite photoanodes for solar water oxidation. Energy Environ Sci 2011, 4: 1759-1764.

[10] Guan G, Kusakabe K, Yamasaki S. Tri-potassium phosphate as a solid catalyst for biodiesel production from waste cooking oil. Fuel Process Technol 2009, 90: 520-524.

[11] Onoda H, Asai K, Takenaka A. Preparation of nickel phosphates with various acidic and basic compounds. J Ceram Process Res 2011, 12: 439-442. 
[12] Onoda H, Taniguchi K, Tanaka I. Additional effects of urea on preparation and acidic properties of lanthanum orthophosphate. Microporous Mesoporous Mater 2008, 109: 193-198.

[13] Onoda H, Sakumura T. Synthesis and pigmental properties of nickel phosphates by the substitution with tetravalent cerium cation. Mater Sci Appl 2011, 2: 1578-1583.

[14] Onoda H, Matsui H, Tanaka I. Improvement of acid and base resistance of nickel phosphate pigment by the addition of lanthanum cation. Mat Sci Eng B 2007, 141: 28-33.

[15] Onoda H, Tange K, Tanaka I. Influence of lanthanum addition on preparation and powder properties of cobalt phosphates. J Mater Sci 2008, 43: 5483-5488.

[16] Onoda H, Sakumura T. Preparation and acidic properties of iron phosphates with sodium dodecyl-sulfate. Phosphorus Res Bull 2012, 27: 28-32. 